\title{
The Negative Impact of a Three Good Things Intervention on Perceived Stress and Psychological Health
}

\author{
Miles Richardson \& David Sheffield \\ University of Derby, Kedleston Road, Derby, DE22 1GB, UK.
}

\begin{abstract}
As part of research to develop an approach to improving nature connectedness the 'three good things' intervention was revised to focus on nature. Participants $(n=35)$ noted three good things in nature, or three good things $(n=33)$ or three factual things $(n=27)$ each day for five days. As planned the nature intervention group showed sustained and significant increases in nature connectedness compared to the other groups. However, the three good things group did not replicate previous results in showing positive well-being outcomes, indeed at two months there was a significant increase in perceived stress and the three good things group was the only group not to show improvements in psychological health.
\end{abstract}

\section{Introduction}

Connecting people more fully with nature has been the focus of several high profile campaigns around the globe (e.g. 30x30 Nature Challenge! by the David Suzuki Foundation, 2013) owing to the state of nature (e.g. Barnosky et al., 2011), the links to pro-environmental behavior (e.g. Frantz \& Mayer, 2014) and the benefits to human health and well-being (e.g. Hartig et al., 2001; Howell et al., 2011; Mayer et al., 2009). This paper extends previously published work on the development of an intervention to increase people's connectedness to nature based on adaptation to the original 'three good things' positive psychology intervention (PPI; Richardson \& Sheffield, 2017). The unpublished element of the research relates to the unexpected negative impact of the original 'three good things' intervention.

Brief PPIs have been associated with increases in well-being including, better health, higher social engagement and greater success (Seligman, Steen, Park \& Peterson, 2005). The three good things PPI involves writing three good things a day, usually for a period of a week or two, an intervention that has been found to increase happiness and decrease depression (Seligman et al., 2005). Research has highlighted the benefits of recording good things on a daily basis and engaging in extended periods of grateful reflection (Seligman et al., 2005; Emmons \& McCullogh, 2003). This ability to be aware of positive things has been shown to improve well-being (Emmons \& McCullough, 2003), and showing appreciation for what you have results in positive affect (Sheldon \& Lyubomirsky, 2006). Experimental evidence demonstrates that increasing positivity broadens the scope of attention, producing creative and flexible thinking, improving thoughts, behaviour and mental health (Fredrickson \& Branigan, 2005).

In order to target nature connectedness, the intervention was simply adjusted to read 'three good things in nature'. In order to test the outcomes of using the three good things in nature intervention an experimental group was compared to a control group directed to write three factual statements each day for five days; a third group completed the original three good things PPI. Connectedness to nature and well-being measures were undertaken at baseline, end of task (one week) and two months after completion. It was predicted that the three good things in nature intervention would lead to improvements in nature connectedness across the timeline and in comparison to the two other groups. We also hypothesized that 
participants in the three good things in nature and three good things groups would show improvements in well-being compared to the control group.

\section{Method}

\subsection{Design}

The study was a $3 \times 3$ mixed design where self-reported scores were taken at three times, pre-intervention, post-intervention and follow up at two months, from participants randomly assigned to one of three writing groups. The control group were required to describe three factual things each day, the second group (referred to as the 'good' group) had to write three good things about each day and the third group (referred to as the 'nature' group) had to write three good things in nature each day.

\subsection{Participants}

Following an invite sent to campus and online students of the University of Derby and circulated by social media, 95 participants took part. The study was designed to detect a medium effect ( $\mathrm{f}=.2$; cf. Tam, Lee \& Chao, 2013), with a power of .9 and an alpha of .05 in 72 participants at follow-up equally divided across three groups. The sample at follow-up comprised of 72 females and 23 males with an age range of 18 to 55 years, mean age of 34.45 years $(\mathrm{SD}=10.14)$. Thirty-seven participants were full or part-time students, 27 were working only, 30 were working and studying part-time and 1 was not working or studying. They were primarily UK $(n=80)$ and non-UK but EU $(n=9)$ based. All participants had to have access to the Internet and their email every day during the week. Participation was voluntary and all participants who completed the study received a $£ 10$ voucher and were entered into a prize draw to win $£ 100$.

\subsection{Materials}

Following a statement of consent, a demographics questionnaire the following scales were completed:

General Health Questionnaire. The GHQ-12 (Goldberg, 1972; Milne, 1992) is a commonly accepted measure of current mental health and psychological well-being that contains items that tap into positive affect (Avey et al., 2010; McKee-Ryan et al., 2005). It is sensitive to short-term variations over multiple time-points. A reliability analysis showed the scale was reliable $(\alpha=0.91)$.

Short Form Nature Relatedness Scale - (NR-6). Based on data from 1200 previous participants, the short form Nature Relatedness Scale (Nisbet \& Zelenski, 2013) is comprised of six items from the 'experience' and 'self' dimensions of the 21-item full scale (Nisbet, Zelenski \& Murphy, 2009). Items from the nature conservation dimension were not included which means NR-6 has a focus on nature relatedness that is useful in the present work. The NR-6 predicts environmental concern, happiness and nature contact and has demonstrated good temporal stability and internal consistency. It has high test-retest correlations and displays trait-like properties, but it is acknowledged that nature relatedness may not be completely fixed (Nisbet \& Zelenski, 2013). A reliability analysis showed the scale was reliable $(\alpha=0.88)$.

Perceived Stress Scale (PSS) - This scale measures perception of stress and how in control of situations in their life participants feel (Cohen, Kamarck \& Mermelstein, 1983). This is a widely used instrument with questions applicable to many different populations. It was selected as a comparator to the nature measures owing to findings relating stress to general health and connectedness to nature (e.g. Frumkin, 2001; Mayer \& Frantz, 2004). A reliability analysis showed the scale was reliable $(\alpha=0.90)$. 


\subsection{Procedure}

Messages with a link to a participant information sheet were sent out requesting participants for a study "exploring the benefits of short writing tasks". A survey website was used to administer the questionnaires and record participants sentences each day following daily reminders.

Participants were randomly allocated conditions. The control group were instructed to write three factual things about a different topic each day. The three good things group were instructed to "write three good things that happened today" and the task guidance stated "Things you list can be small things or quite important, things. For example, it could be that someone gave you a compliment; something you achieved; something trivial that you enjoyed or good news about something/someone." The nature group were instructed to "write three good things in nature that you noticed today."

After completing the five days another email was sent out with a link to the questionnaires except for GHQ-12 or PSS owing to the timescales in their wording. Two months later the full questionnaire pack with final debrief was sent out by email. The study was repeated over several weeks from April to August 2013.

\subsection{Ethical Considerations}

The study was approved by the department's Ethics Committee and met the conditions of the British Psychological Society's (BPS) Code of Conduct and ethical principles for carrying out research.

\section{Results}

Table 1 shows the means and standard deviations for the nature connectedness measures by group at pre-intervention baseline, post-intervention at one week and follow-up at two months. It also shows the one-week and two months changes in these measures.

\begin{tabular}{|c|c|c|c|c|c|c|}
\hline & & Pre & Post & 2 months & $\begin{array}{l}1 \text { week } \\
\text { change }\end{array}$ & $\begin{array}{l}2 \text { month } \\
\text { change }\end{array}$ \\
\hline \multirow{2}{*}{ Control } & Mean & 3.41 & 3.56 & 3.46 & 0.14 & 0.05 \\
\hline & SD & 0.99 & 0.92 & 1.09 & 0.42 & 0.62 \\
\hline \multirow[t]{2}{*}{ Good } & Mean & 3.60 & 3.74 & 3.60 & 0.14 & 0.00 \\
\hline & SD & 0.78 & 0.81 & 0.80 & 0.44 & 0.61 \\
\hline \multirow[t]{2}{*}{ Nature } & Mean & 3.09 & 3.39 & 3.45 & 0.30 & 0.36 \\
\hline & SD & 0.91 & 0.70 & 0.80 & 0.43 & 0.42 \\
\hline \multirow[t]{2}{*}{ Total } & Mean & 3.36 & 3.56 & 3.51 & 0.20 & 0.15 \\
\hline & SD & 0.91 & 0.81 & 0.88 & 0.43 & 0.57 \\
\hline
\end{tabular}

Table 1. NR-6 scores by time point and condition.

\subsection{NR-6 Results}

A 3 (Group) x 3 (Time) factorial repeated measures ANOVA was conducted on the NR-6 scores shown in table 1 . Group was not statistically significant, $\mathrm{F}(2,92)=1.43, p=$ $0.25, \eta^{2}=0.03$. Mauchly's test indicated that the assumption of sphericity had been violated $\left(\mathrm{X}^{2}(2)=8.87, p=0.012\right)$, therefore degrees of freedom were corrected using GreenhouseGeisser estimates of sphericity $(\varepsilon=0.92)$. Time had a significant impact on NR-6 scores, $\mathrm{F}(1.83,168.37)=8.07, p<0.01, \eta^{2}=0.01$. There was also a significant interaction effect between time and intervention group, $\mathrm{F}(3.66,168.34)=2.82, p=0.03, \eta^{2}=0.01$, 
demonstrating that the interventions were having different effects. These results indicate that further analysis is worthwhile and, owing to the notable, but non-significant $(F(2,92)=2.84$, $p=0.06$ ), range of NR-6 scores at the pre-intervention baseline, the change scores at one week and two month follow-up were analysed across groups, in addition to paired t-tests for within group differences.

Visual inspection of the data suggested that participants' change in NR-6 over the study week was greater for the nature group compared to the control group, but this difference was statistically non-significant, $t(60)=-1.46, p=0.15, d=0.38$. Similarly, differences between the nature and good things group over the study week were also found to be non-significant, $t(66)=-1.53, p=0.13, d=0.38$. However, the difference in changes in NR-6 at two months were significantly greater for the nature group compared to the control group, $t(43.48)=-2.24, p=0.03, d=0.58$, and between the nature and good things group, $t(66)=-2.90, p<0.01, d=0.71$.

Paired samples t-tests were used to further investigate differences within each group. Within the nature group, there was statistically significant increase from pre-intervention baseline NR-6 to post-intervention NR-6, $\mathrm{t}(34)=4.14, p<0.01, d=0.37$, and from preintervention baseline NR-6 to two month follow-up NR-6, $\mathrm{t}(34)=5.08, p<0.01, d=0.42$. In contrast, pre-intervention baseline to post-intervention and two month follow-up differences in NR-6 were non-significant in both the control and good things groups, $p>0.05$, all $d<$ 0.18 .

A $\mathrm{X}^{2}$ test was performed and a statistically significant relationship was found between group and frequency of NR-6 improvement at two months (two month post-intervention minus pre-intervention), $\mathrm{X}^{2}(2, \mathrm{~N}=95)=6.80, p=0.03$, with $80 \%$ of those in the nature group showing an increase in NR-6 compared to $51.9 \%$ and $54.5 \%$ in the control and good things group, respectively.

\subsection{Psychological Health}

It was hypothesized that participants in the three good things in nature and three good things groups would show improvements in well-being compared to the control group. Table 2 shows the GHQ-12 results for each group. Using a one-way ANOVA no significant differences between groups were found at baseline for GHQ-12, $\mathrm{F}(2,92)=0.10, p=0.90$. There were no differences in the changes in GHQ-12 between the groups, $\mathrm{F}(2,92)=0.864, p$ $=0.43$. However, the control and nature groups both showed statistically significant improvements in well-being over two months as measured by GHQ-12; for control group, $\mathrm{t}(26)=3.30, p<0.01, d=0.58$ and for nature group, $\mathrm{t}(34)=4.19, p<0.01, d=0.70$, while the good group showed no improvement, $\mathrm{t}(32)=1.57, p=0.13, d=0.33$.

\begin{tabular}{ll|cccccc} 
& & \multicolumn{4}{|c}{ GHQ } & PSS & \\
& & GHQ & $\begin{array}{c}\text { 2 } \\
\text { Pre }\end{array}$ & $\begin{array}{c}\text { GHQ } \\
\text { months }\end{array}$ & $\begin{array}{c}\text { PSS } \\
\text { Change }\end{array}$ & $\begin{array}{c}\text { Pre } \\
\text { months }\end{array}$ & $\begin{array}{c}\text { PSS } \\
\text { Change }\end{array}$ \\
\hline Control & Mean & 13.78 & 10.59 & -3.19 & 21.11 & 20.63 & -0.48 \\
& SD & 6.30 & 4.57 & 5.02 & 7.45 & 7.77 & 7.05 \\
Good & Mean & 13.88 & 11.67 & -2.21 & 19.91 & 24.06 & 4.15 \\
& SD & 7.04 & 6.37 & 8.09 & 8.05 & 8.65 & 6.52 \\
\multirow{5}{*}{ Total } & Mean & 14.46 & 10.14 & -4.31 & 20.63 & 20.09 & -0.54 \\
& SD & 6.24 & 6.16 & 6.09 & 7.94 & 8.15 & 5.75 \\
& Mean & 14.06 & 10.80 & -3.26 & 20.52 & 21.62 & 1.11 \\
& SD & 6.48 & 5.81 & 6.59 & 7.77 & 8.33 & 6.72 \\
\hline
\end{tabular}

Table 2. GHQ-12 and PSS results by condition. 
Finally, using a one-way ANOVA, there were significant differences in the changes in PSS between the groups, $\mathrm{F}(2,92)=5.717, p<0.01$. Further analysis showed statistically significant increases in perceived stress over two months as measured by PSS for the good group, $\mathrm{t}(32)=-3.66, p<0.01, d=0.50$. No differences were found in the control group, $\mathrm{t}(26)$ $=0.36, p=0.73, d=0.06$ and nature group, $\mathrm{t}(34)=0.56, p=0.58, d=0.07$.

\subsection{Linguistic Analysis of Sentences}

Linguistic Inquiry and Word Count - Linguistic Inquiry and Word Count (LIWC) software (Pennebaker, Francis \& Booth, 2007) was used to analyse word frequencies in the sentences. The nature group wrote 272 words per participant on average, good group 284 words and control group 144 words. The frequency analysis using LIWC super-ordinate level categories, see table 3, shows broadly that the nature group tended to write more often about the perception (e.g. hearing and seeing) of things; indicated by the frequency of perceptual process and articles associated with nouns. The good group were more likely to write positively about actions related to themselves, achievements, work and social processes in the past tense. For example, "Stood up for myself at work", "Provided sound solutions for a client to facilitate access to work" and "I received help from my friend". The control group's topic focus was directed to factual items each day, so the content analysis provides a manipulation check.

\begin{tabular}{clrlcl} 
Control & Category & Good & Category & Nature & Category \\
\hline 11.26 & Prepositions & 17.05 & Relativity & 19.75 & Relativity \\
10.92 & Relativity & 14.96 & Prepositions & 16.47 & Prepositions \\
9.85 & Cognitive Proc. & 12.47 & Verbs & 14.43 & Articles \\
8.74 & Biological Proc. & 12.15 & Cognitive Proc. & 8.25 & Cognitive Proc. \\
8.08 & Verbs & 10.48 & Pers. Pronouns & 7.31 & Perceptual Proc. \\
7.56 & Articles & 8.80 & Affect & 5.72 & Verbs \\
7.54 & Pers. Pronouns & 8.68 & Social Proc. & 4.22 & Pers. Pronouns \\
5.54 & Percept. Proc. & 8.48 & Past Tense & 3.86 & Affect \\
4.74 & Past Tense & 7.69 & Articles & 3.33 & Positive Emotion \\
4.28 & Work & 6.94 & Positive Emotion & 2.94 & Past Tense \\
4.03 & Social Processes & 4.61 & Work & 2.23 & Present Tense \\
3.97 & Leisure & 3.18 & Perceptual Proc. & 2.17 & Leisure \\
2.85 & Present Tense & 3.01 & Present Tense & 2.05 & Home \\
2.69 & Affect & 2.97 & Achievement & 2.04 & Social Proc. \\
2.13 & Positive Emotion & 2.83 & Leisure & 1.39 & Quantifiers \\
1.67 & Home & 2.31 & Quantifiers & 1.23 & Biological Proc. \\
1.46 & Quantifiers & 2.06 & Biological Proc. & 0.91 & Achievement \\
1.36 & Achievement & 1.35 & Home & 0.70 & Work \\
\hline
\end{tabular}

Table 3. Ranked frequency analysis of linguistic categories used during the writing task.

\section{Discussion}

It was predicted that the three good things in nature intervention would lead to improvements in nature connectedness over time and when compared to the control and good things groups. The sustained and significant increases in both the nature connectedness measures within the nature group when compared to the other groups give good reason to 
consider the three good things in nature intervention a success. More detailed discussion can be found in Richardson \& Sheffield (2017). More widely, the existing three good things PPI did not replicate previous results in showing positive well-being outcomes, indeed at two months there was a significant increase in perceived stress and the good group was the only group not to show improvements in psychological health.

The well-being results may be due to the shorter five-day intervention period compared to the more frequently used one to two week interventions previously published, and that a non-clinical sample was recruited (Sin \& Lyubomirsky, 2009), although this was the same across the three conditions. The linguistic analysis of the original good things group shows that they used words associated with positive emotions to focus on themselves, work, achievements and social relationships in the past tense. The significant increase in perceived stress could be related to the higher frequency of work-related words, with participants potentially revisiting issues occurring during the day (e.g. standing up for themselves at work) while identifying their good things.

In conclusion, the simple intervention of noting three good things in nature each day can deliver sustained increases in nature connectedness required to enhance well-being and sustainable behavior towards the natural world while also providing a less individualistic and work based focus.

\section{References}

Barnosky, A. D., Matzke, N., Tomiya, S., Wogan, G. O. U., Swartz, B., Quental, T. B., Marshall, C., McGuire, J. L., Lindsey, E. L., Maguire, K. C., Mersey, B. \& Ferrer, E. A. (2011). Has the Earth's sixth mass extinction already arrived? Nature, 471, 51-57 doi:10.1038/nature09678

Cohen, S., Kamarck, T., \& Mermelstein, R. (1983). A global measure of perceived stress. Journal of Health and Social Behavior, 24, 385-396.

David Suzuki Foundation (2013). 30x30 Nature Challenge! Retrieved September 22, 2013 from http://30x30.davidsuzuki.org

Emmons, R. A. \& McCullough, M. E. (2003). Counting blessings versus burdens: An experimental investigation of gratitude and subjective well-being in daily life. Journal of Personality and Social Psychology. 84(2), 377-389.

Frantz, C.M. \& Mayer, F.S. (2013). The importance of connection to nature in assessing environmental education programs. Studies in Educational Evaluation. Retrieved February 10, 2014 from http://www.sciencedirect.com/science/article/pii/S0191491X13000436

Fredrickson, B.L. \& Branigan, C. (2005). Positive emotions broaden the scope of attention and thought-action repertoires. Cognition and Emotion, 19, 313-332.

Frumkin, H. (2001). Beyond toxicity: Human health and the natural environment. American Journal of Preventive Medicine, 20, 234-240.

Goldberg, D.P. (1972). The detection of psychiatric illness by questionnaire: A technique for the identification and assessment of non-psychotic illness. London: Oxford University Press.

Hartig, T., van den Berg, A., Hägerhäll, C., Tomalak, M., Bauer, N., Hansmann, R., Ojala, A., Syngollitou, E., Carrus, G., van Herzele, A., Bell, S., Camilleri Podesta, M.T., \& Waaseth, G. (2011). Health benefits of nature experience: Psychological, social and cultural processes. In Nilsson, K., Sangster, M., Gallis, C., Hartig, T., De Vries, S., Seeland, K., \& Schipperijn, J. (Eds.), Forests, trees, and human health (pp. 127-168). Dordrecht: Springer. doi:10.1007/978-90-481-9806-1 
Howell, A.J., Dopko, R.L., Passmore, H.A., \& Buro, K. (2011). Nature connectedness: Associations with well-being and mindfulness. Personality and Individual Differences, 51, 166-171. doi:10.1016/j.paid.2011.03.037

Milne, D. (ed.) (1992). Interpersonal Difficulties, Assessment, A Mental Health Portfolio. Windsor: NFER-Nelson.

Nisbet, E.K.L., Zelenski, J.M., \& Murphy, S.A. (2009). The nature relatedness scale: Linking individuals' connection with nature to environmental concern and behavior. Environment and Behavior, 41, 715-740. doi:10.1177/0013916508318748

Nisbet, E.K \& Zelenski, J.M. (2013). The NR-6: A new brief measure of nature relatedness. Frontiers in Psychology. Retrieved September 22, 2013 from http://www.frontiersin.org/Journal/abstract/63438

Pennebaker, J.W., Chung, C.K., Ireland, M., Gonzales, A., \& Booth, R. (2007). The development and psychometric properties of LIWC2007. Austin, TX: LIWC.net.

Richardson, M., \& Sheffield, D. (2017). Three good things in nature: noticing nearby nature brings sustained increases in connection with nature. Psyecology, 8(1), 1-32.

Seligman, M.E.P (1998). Learned optimism (2nd ed.). New York: Pocket Books.

Seligman, M.E.P., Steen, T.A., Park, N., \& Peterson, C. (2005). Positive Psychology Progress. Empirical Validation of Interventions. American Psychologist. 60, 410-421.

Sheldon, K.M., \& Lyubomirsky, S. (2006). How to increase and sustain positive emotion: The effects of expressing gratitude and visualizing best possible selves. The Journal of Positive Psychology. 1(2), 73-82.

Sin, N.L., \& Lyubomirsky, S. (2009). Enhancing well-being and alleviating depressive symptoms with positive psychology interventions: A practice-friendly metaanalysis. Journal of clinical psychology, 65(5), 467-487.

Tam, K.-P., Lee, S.-L., \& Chao, M.M. (2013). Saving Mr. Nature: Anthropomorphism enhances connectedness to and protectiveness toward nature. Journal of Experimental Social Psychology, 49, 3. doi:10.1016/j.jesp.2013.02.001 